\title{
Predictors of fetal macrosomia in Iringa, Tanzania: a case-control study
}

\author{
Emmanuel Imani Ngadaya, Maria \\ Angelica Rweyemamu, (D) Ipyana \\ Hudson Mwampagatwa and Athanase \\ Gervase Lilungulu
}

Department of Obstetrics and

Gynecology, School of Medicine and

Dentistry, University of Dodoma, Tanzania

Correspondence:

Emmanuel Imani Ngadaya

ngadayaemmanuel@gmail.com

Submitted: June 2021

Accepted: October 2021

Published: November 2021
Citation: Ngadaya et al. Predictors of fetal macrosomia in Iringa, Tanzania: a case-control study. South Sudan Medical Journal 2021;14(4):116-121 (C) 2021 The Author (s) License: This is an open access article under CC BY-NC DOI: https:// dx.doi.org/10.4314/ssmj.v14i4.3

\section{Abstract}

Introduction: It is challenging to predict fetal macrosomia before delivery. This study aimed at assessing predictors of fetal macrosomia at Iringa Regional Referral Hospital in Tanzania from June to December 2020.

Method: An unmatched case-control study with 216 participants of whom 72 were cases - women who delivered babies weighing $\geq 4000 \mathrm{~g}$ - and 144 were controls - women who delivered babies weighing $2500 \mathrm{~g}$ to $3499 \mathrm{~g}$. The purposive sampling technique described below was employed to recruit both controls and cases. SPSS version 25 software program was used for data entry and analysis.

Results: Of the 216 participants, 116 (53.7\%) were aged between $25-34$ years (standard deviation 6.0). The majority of $132(61.1 \%)$ delivered at a gestational age of $37-39$ weeks +6 days of whom 17 (23.6\%) were cases and $115(79.86 \%)$ were controls. The predictors of fetal macrosomia were advanced gestation age $(\mathrm{AOR}=8.10,95 \%$ CI 3.66-17.91, $\mathrm{p}=<0.0001)$ and diabetes mellitus during pregnancy $(\mathrm{AOR}=14.94,95 \% \mathrm{CI} 1.60-39.91, \mathrm{p}=$ $0.0178)$

Conclusion: Women with higher gestational age and gestational diabetes mellitus are at an increased risk of delivering a baby with macrosomia at Iringa Regional Referral Hospital. An early plan for the mode of delivery, such as labour induction, will aid the prevention of advanced gestational age. Ensuring a healthy diet and physical exercises in our communities will help to reduce diabetes mellitus and hence fetal macrosomia.

Keywords: Macrosomia, Predictors, Tanzania

\section{Introduction}

Fetal macrosomia is widely defined as a birth weight of $\geq 4000 \mathrm{~g}$ or birth weight greater than the 90th percentile at birth. ${ }^{[1]}$ The worldwide prevalence of fetal macrosomia is $0.5 \%$ to $15 \%$ of all pregnancies. ${ }^{[2]}$ The prevalence in developed countries ranges from $15-20 \%$ due to excess nutritional intake, obesity, and diabetes mellitus. ${ }^{[1]}$ In Africa, the prevalence ranges from $2 \%$ to $9 \%$ and the reasons include multiparity and variations in maternal weight gain during pregnancy. ${ }^{[1,3-5]}$

The predictors of fetal macrosomia studied to date include a previous history of delivering a macrosomic baby, multiparity, male fetus, uncontrolled diabetes mellitus, gestational diabetes, gestational age, maternal weight gain during pregnancy, parental height, post-term pregnancy, and ethnicity. ${ }^{[2,6]}$ Fetal macrosomia has been linked to adverse maternal and fetal outcomes such as postpartum haemorrhage, the leading cause of maternal mortality, and neonatal death. ${ }^{[3,7]}$ The gold standard for diagnosing fetal macrosomia is magnetic resonant imaging (MRI) which is rarely available at many facilities in developing countries. ${ }^{[6]}$ Clinical examination and obstetric ultrasound are less accurate compared to MRI. ${ }^{[6,8]}$ This study aimed to assess the predictors of fetal macrosomia in Iringa, Tanzania. 


\section{Method}

A hospital-based unmatched case-control study was designed involving term pregnant women with a singleton birth at the Department of Obstetrics and Gynaecology at Iringa Regional Referral Hospital from June to December 2020. A total of 216 women were included of whom the 72 who delivered babies weighing $\geq 4000 \mathrm{~g}$ were considered as cases and the 144 women who delivered babies weighing $2500 \mathrm{~g}$ to $3499 \mathrm{~g}$ were taken as controls. The reasons for selecting these weight groups is:

1. Cases (macrosomic group) - women who delivered babies of birthweight of $4000 \mathrm{~g}$ and above. This agrees with the globally standard accepted definition of fetal macrosomia.

2. Controls (normal weight babies) - women who delivered babies of $2500 \mathrm{~g}$ to $3499 \mathrm{~g}$, the cut-off lower limit was $2500 \mathrm{~g}$ because below $2500 \mathrm{~g}$ is a low birth weight' and in Tanzania, 3500g and above are considered as big babies /macrosomia.

We used a modified World Health Organization criteria to diagnose diabetes mellitus during pregnancy. A 2-hour $75 \mathrm{~g}$ oral glucose tolerance test (OGTT) was used. Study participants who were known to be diabetic were not included in the test. Participants were required to fast for a minimum of 8 hours before the test, the fasting blood glucose was obtained. After 2 hours of taking the oral glucose, blood glucose was measured. All women with a fasting plasma glucose level of $\geq 7.0 \mathrm{mmol} / \mathrm{l}(126 \mathrm{mg} / \mathrm{dl})$ or a 2-hour plasma glucose of $\geq 11.1 \mathrm{mmol} / \mathrm{l}(200 \mathrm{mg} / \mathrm{dl})$ were considered as women with diabetes during pregnancy

Data were analyzed using SPSS, version 25.0 (IBM Inc., Chicago). Ethical clearance was obtained from the University of Dodoma Directorate of Research and Publication and informed consent was obtained from the participants.

Table 1. Social demographic characteristics of the participants $(\mathrm{N}=216)$

\begin{tabular}{|c|c|c|c|}
\hline Variable & Total $n=216 n$ (\%) & Cases $n=72 n(\%)$ & Control $n=144 n(\%)$ \\
\hline \multicolumn{4}{|l|}{ Child characteristics } \\
\hline \multicolumn{4}{|l|}{ Sex } \\
\hline Male & $124(57.4)$ & $45(62.5)$ & 79 (54.9) \\
\hline Female & $92(42.6)$ & $27(37.5)$ & $65(45.1)$ \\
\hline \multicolumn{4}{|l|}{ Maternal characteristics } \\
\hline \multicolumn{4}{|l|}{ Maternal age (years) } \\
\hline $15-24$ & $64(29.6)$ & $11(15.3)$ & $53(36.8)$ \\
\hline $25-34$ & $116(53.7)$ & $44(61.1)$ & $72(50.0)$ \\
\hline $35+$ & $36(16.7)$ & $17(23.6)$ & $19(13.2)$ \\
\hline \multicolumn{4}{|l|}{ Residence } \\
\hline Rural & $94(43.5)$ & 30 (41.7) & $64(44.4)$ \\
\hline Urban & $122(56.5)$ & $42(58.3)$ & $80(55.6)$ \\
\hline \multicolumn{4}{|l|}{ Parity } \\
\hline 1 & $73(33.8)$ & $15(20.8)$ & $58(40.3)$ \\
\hline 2 & $66(30.6)$ & $19(26.4)$ & $47(32.6)$ \\
\hline 3 & $44(20.4)$ & $18(25.0)$ & $26(18.1)$ \\
\hline $4+$ & $33(15.3)$ & $20(27.8)$ & $13(9.0)$ \\
\hline \multicolumn{4}{|l|}{ Gestation age (weeks) } \\
\hline $37-39$ weeks +6 days & $132(61.1)$ & $17(23.6)$ & $115(79.9)$ \\
\hline $40-41$ weeks +6 days & $68(31.5)$ & $45(62.5)$ & $23(16.0)$ \\
\hline $42+$ & $16(7.1)$ & 10 (13.9) & $6(4.2)$ \\
\hline \multicolumn{4}{|l|}{ Level of education } \\
\hline No formal education & $34(15.7)$ & $12(16.7)$ & $22(15.3)$ \\
\hline Primary & $106(49.1)$ & $28(38.9)$ & $48(33.3)$ \\
\hline Secondary and above & 76 (35.2) & $32(44.4)$ & $74(51.4)$ \\
\hline
\end{tabular}


Table 2. Predictors of fetal macrosomia ( $\mathrm{N}=\mathbf{2 1 6})$

\begin{tabular}{|c|c|c|c|c|}
\hline \multirow[t]{2}{*}{ Variable } & \multicolumn{2}{|c|}{ Macrosomia } & \multirow[b]{2}{*}{$x^{2}$} & \multirow[b]{2}{*}{ p-value } \\
\hline & $\begin{array}{l}\text { Case } \\
n=72\end{array}$ & $\begin{array}{l}\text { Control } \\
n=144\end{array}$ & & \\
\hline \multicolumn{5}{|l|}{ Child's characteristics } \\
\hline Sex & & & 1.1455 & 0.285 \\
\hline Male & $45(62.5)$ & 79 (54.9) & & \\
\hline Female & $27(37.5)$ & $65(45.1)$ & & \\
\hline \multicolumn{5}{|l|}{ Maternal factors } \\
\hline Age - years & & & 11.7363 & 0.003 \\
\hline $15-24$ & $11(15.3)$ & $53(36.8)$ & & \\
\hline $25-34$ & $44(61.1)$ & $72(50.0)$ & & \\
\hline$\geq 35$ & $17(23.6)$ & $19(13.2)$ & & \\
\hline Residence & & & 0.1507 & 0.698 \\
\hline Rural & $30(41.7)$ & $64(44.4)$ & & \\
\hline Urban & $42(58.3)$ & $80(55.6)$ & & \\
\hline Gestation age - days & & & 63.9846 & $<0.0001$ \\
\hline $37-39$ & $17(23.6)$ & 115 (79.9) & & \\
\hline 40 - 41(+6 days) & $45(62.5)$ & $23(16.0)$ & & \\
\hline $42+$ & $10(13.9)$ & $6(4.2)$ & & \\
\hline Maternal Body Mass Index $(\mathrm{kg} / \mathrm{m} 2)$ & & & 0.8827 & 0.643 \\
\hline 18.5- 24.9 & $27(37.5)$ & $51(35.4)$ & & \\
\hline 25.0-29.90 & $27(37.5)$ & $59(41.0)$ & & \\
\hline$\geq 30.0$ & $18(25.0)$ & $30(20.8)$ & & \\
\hline Previous history of delivering a macrosomic baby & & & 30.4912 & $<0.0001$ \\
\hline Yes & $35(48.6)$ & $20(13.9)$ & & \\
\hline No & $37(51.4)$ & $124(86.1)$ & & \\
\hline Diabetes Mellitus & & & & $<0.0001^{*}$ \\
\hline Non diabetic & $62(86.1)$ & $143(99.3)$ & & \\
\hline Diabetic & 10 (13.9) & $1(0.7)$ & & \\
\hline Parity & & & 18.1653 & $<0.0001$ \\
\hline 1 & $15(28.4)$ & $58(40.3)$ & & \\
\hline 2 & $19(26.4)$ & $47(32.6)$ & & \\
\hline 3 & $18(25.0)$ & $26(18.1)$ & & \\
\hline $4+$ & $20(27.8)$ & $13(9.0)$ & & \\
\hline Weight gain during pregnancy (kg) & & & 0.7648 & 0.382 \\
\hline$\leq 11$ & $38(52.8)$ & $85(59.0)$ & & \\
\hline$>11$ & $34(47.2)$ & $59(41.0)$ & & \\
\hline
\end{tabular}

$p$-value with * indicates $p$-value calculated by the Fisher exact test 


\section{Results}

There were 79 (54.9\%) male babies and 65 (45.1\%) female babies. The mean age of the 216 mothers was 28.5 years (standard deviation 6.0 years); 116 (53.7\%) of participants were aged between $25-34$ years of whom 44 $(61.1 \%)$ were cases and $72(5 \%)$ were controls. Seventyeight $(33.8 \%)$ were primiparous of whom $15(20.83 \%)$ were cases and 58 (40.28) were controls. Table 1.

\section{The predictors of fetal macrosomia}

This study found that, among the maternal factors, gestation age $\geq 40$ weeks ( $\mathrm{p}$-value $=<0.0001$ ), a previous history of macrosomic baby ( $\mathrm{p}$-value $=<0.0001)$, diabetes mellitus in pregnancy, higher parity $(\mathrm{p}$-value $=<0.0001)$ and higher maternal age ( $\mathrm{p}$-value $=0.0028$ ) were predictors of fetal macrosomia on cross tabulation as shown in Table 2.

In this study, women with advanced gestation age $(\geq 40$ weeks) were eight times more likely to give birth to a macrosomic baby compared to women who delivered at a gestation age of 37 to 39 weeks $(A O R=8.10,95 \%$ $\mathrm{CI}=3.66-17.91, \mathrm{p}=<0.0001)$. Women with diabetes mellitus were 14 times more likely to give birth to a macrosomic baby compared to women without diabetes mellitus (AOR=14.94, 95\% CI=1.60-39.91, $\mathrm{p}=0.0178)$ as shown in Table 3.

\section{Discussion}

In Taiwan and Indonesia, fetal macrosomia has been associated with maternal overweight and obesity. ${ }^{[10,11]}$ This is contrary to the finding in this study in which body mass index did not predict fetal macrosomia. Although not statistically significant, excessive weight gain before and during pregnancy has been linked to decreasing insulin sensitivity which facilitates the transfer of glucose via the placenta to the growing fetus hence leading to increasing fetal size. ${ }^{[11,12]}$ These two studies were cohort studies conducted for a longer duration and with a larger sample size compared to our study. This may explain why BMI was significantly associated in their study and not in ours.

The predictors of fetal macrosomia in Malaysia included increasing maternal age, increasing BMI, increasing weight gain during pregnancy, higher parity, and diabetes mellitus during pregnancy. ${ }^{[14]}$ In this study advanced maternal age, maternal BMI, maternal weight gain

Table 3. Logistic regression of factors associated with fetal macrosomia ( $N=216)$

\begin{tabular}{|c|c|c|c|c|c|c|c|c|}
\hline \multirow[t]{2}{*}{ Variable } & \multirow[t]{2}{*}{ OR } & \multicolumn{2}{|c|}{$95 \% \mathrm{Cl}$ OR } & \multirow[t]{2}{*}{ p-value } & \multirow[t]{2}{*}{ AOR } & \multicolumn{2}{|c|}{$95 \% \mathrm{Cl}$ AOR } & \multirow[t]{2}{*}{ p-value } \\
\hline & & & & & & Lower & Upper & \\
\hline \multicolumn{9}{|c|}{ Maternal Age (years) } \\
\hline $15-24$ & Ref. & & & & & & & \\
\hline $25-34$ & 2.94 & 1.39 & 6.23 & 0.0048 & 1.75 & 0.65 & 4.71 & 0.2666 \\
\hline$\geq 35$ & 4.31 & 1.72 & 10.84 & 0.0019 & 1.04 & 0.26 & 4.234 & 0.9584 \\
\hline \multicolumn{9}{|l|}{ Gestation age } \\
\hline $37-39$ & Ref. & & & & & & & \\
\hline 40 - 41(+6 days) & 13.24 & 6.47 & 27.07 & $<0.0001$ & 8.10 & 3.66 & 17.91 & $<0.0001$ \\
\hline$\geq 42$ & 11.28 & 3.63 & 35.01 & $<0.0001$ & 8.67 & 2.53 & 29.74 & 0.0006 \\
\hline \multicolumn{9}{|l|}{ Parity } \\
\hline 1 & Ref. & & & & & & & \\
\hline 2 & 1.56 & 0.72 & 3.41 & 0.2608 & 1.02 & 0.38 & 2.75 & 0.9713 \\
\hline 3 & 2.68 & 1.17 & 6.12 & 0.0196 & 1.47 & 0.47 & 4.60 & 0.5072 \\
\hline $4+$ & 5.95 & 2.42 & 14.63 & 0.0001 & 1.78 & 0.46 & 6.94 & 0.4068 \\
\hline \multicolumn{9}{|c|}{$\begin{array}{l}\text { History of delivery of a } \\
\text { macrosomic baby }\end{array}$} \\
\hline No & Ref. & & & & & & & \\
\hline Yes & 5.87 & 3.03 & 11.36 & $<0.0001$ & 2.34 & 0.90 & 6.09 & 0.0815 \\
\hline \multicolumn{9}{|l|}{ Diabetes mellitus } \\
\hline Non-diabetic & Ref. & & & & & & & \\
\hline Diabetic & 0.04 & 0.01 & 0.35 & 0.0031 & 14.94 & 1.60 & 39.91 & 0.0178 \\
\hline
\end{tabular}


during pregnancy, and higher parity were not associated with fetal macrosomia although diabetes mellitus during pregnancy was strongly associated. Ours was a case-control study with only 216 participants while in Malaysia it was a cross-sectional study with 2332 participants, a difference that may explain why findings differ. Diabetes mellitus during pregnancy leads to increasing fetal adiposity hence an increase in fetal weight leading into macrosomia. ${ }^{[14]}$

Advanced gestation age was the commonest predictor of fetal macrosomia in this study and is similar to findings in Sydney in which it was estimated that a fetus gains $176.5 \mathrm{~g}$ per week; this may explain why advanced gestation age predisposes a woman to deliver a macrosomic baby. ${ }^{[15]}$

In Tanzania and Ethiopia, the predictors of fetal macrosomia were a maternal weight above $80 \mathrm{~kg}$, multiparity, diabetes mellitus during pregnancy, and maternal pre-pregnancy BMI and pregnancy weight gain respectively while maternal age and previous history of delivering a macrosomic baby were found in both studies. [5,9] These findings are at variance with those in our study where only higher gestation age and gestational diabetes mellitus during pregnancy were significantly associated with fetal macrosomia.

Efforts to prevent diabetes mellitus which may result in fetal macrosomia should be one of the community interventions. Diabetes mellitus can be prevented by first ensuring a healthy balanced diet in our communities and also by educating families on physical exercises. It is best for women with advanced gestation age who are at risk of fetal macrosomia to seek care early and the mode of delivery determined. Early labour induction or a possible Caesarean Section play an important role in preventing dangerous obstetric outcomes of fetal macrosomia.

\section{Conclusion}

Women with higher gestational age and gestational diabetes mellitus are at an increased risk of delivering a baby with macrosomia at Iringa Regional Referral Hospital. An early plan for the mode of delivery, such as labour induction, will aid the prevention of advanced gestational age. Ensuring a healthy diet and physical exercises in our communities will help to reduce diabetes mellitus and hence fetal macrosomia.

Acknowledgement: We thank Dr Alfred Laison Mwakalebela and Dr. Malangalila, Scholastica Mathew of Iringa Regional Referral Hospital for supporting this study as well as all study participants.

References

1. Dennedy MC, Dunne F. Macrosomia: Defining the problem worldwide. Lancet $2013 ; 381(9865): 435-436$.https://doi. org/10.1016/S0140-6736(12)62090-X
2. Black MH LJ, Sacks DA, Xiang AH. The relative contribution of prepregnancy overweight and obesity, gestational weight gain, and IADPSGdefined gestational diabetes mellitus to fetal overgrowth. Diabetes Care 2013;36:56-62 .https://doi.org/10.2337/dc12-0741

3. Pagani G, Palai N, Zatti S, Fratelli N, Prefumo F, and Frusca T. Fetal weight estimation in gestational diabetic pregnancies: Comparison between conventional and three-dimensional fractional thigh volume methods using gestation-adjusted projection. Ultrasound Obstet. Gynecol.2014; 43(1):72-76.https://doi.org/10.1002/uog.12458

4. Akindele RN, Audu LI, Mokuolu OA. Macrosomic births in Abuja: A case-control study of predisposing factors and early neonatal outcome. Niger J Clin Pract 2017;20 (3):320-7. https://doi.org/10.4103/1119-3077.196060

5. Said AS, Manji KP. Risk factors and outcomes of fetal macrosomia in a tertiary center in Tanzania: a case-control study. BMC Pregnancy Childbirth 2016;16 (1):1-8.https://doi.org/10.1186/s12884016-1044-3

6. Maher MHK, Soltani R, Zeinalzadeh AH, and Pourasghar S. Complications and risk factors of neonatal macrosomia: A case-control study. Iran. J. Neonatal 2018.https://doi.org/10.22038/ ijn.2018.10488

7. Bandika VL, Were FN, Simiyu ED, and Oyatsi DP. Hypoglycemia and hypocalcemia as determinants of admission birth weight criteria for term stable low-risk macrosomic neonates. Afr. Health Sci. 2014;14(3):510-516. https://doi.org/10.4314/ ahs.v14i3.3

8. Kadji C, Cannie MM, Resta S, Guez D, Abi-Khalil F, De Angelis R, Jani JC. Magnetic resonance imaging for prenatal estimation of birthweight in pregnancy: a review of available data, techniques, and future perspectives. Am J Obstet Gynecol. 2019;220(5):428-439. https://doi.org/10.1016/j. ajog.2018.12.031

9. Tela FG, Bezabih AM, Adhanu AK, Tekola KB. Fetal macrosomia and its associated factors among singleton live births in private clinics in Mekelle city, Tigray, Ethiopia. BMC Pregnancy Childbirth 2019;19(1):1-6. https://doi.org/10.1186/s12884019-2379

10. Hung TH and Hsieh TT. Pregestational Body Mass Index, Gestational Weight Gain, and Risks for Adverse Pregnancy Outcomes Among Taiwanese Women: a Retrospective Cohort Study. 
Taiwanese Journal of Obstetrics \& Gynecology 2016.55 (4):575-81. https://doi.org/10.1016/j. tjog.2016.06.016

11. Soltani H, Lipoeto NL, Fair FJ, Kilner K, and Yusrawati Y. Pre-pregnancy body mass index and gestational weight gain and their effects on pregnancy and birth outcomes: A cohort study in West Sumatra, Indonesia. BMC WomensHealth 2017;17(1):1-12.https://doi.org/10.1186/ s12905-017-0455-2

12. Pongcharoen T, Gowachirapant S, Wecharak P, Sangket N, Winichagoon P. Pre-pregnancy body mass index and gestational weight gain in Thai pregnant women as risks for low birth weight and macrosomia. Asia Pac J Clin Nutr. 2016;25(4):810-817.https://doi.org/10.6133/ apjen.092015.41
13. Vickers MH. Developmental programming and transgenerational transmission of obesity. Ann. Nutr. Metab.2014;64(1):26 - 34. https://doi. org/10.1159/000360506

14. Yadav $\mathrm{H}$ and Lee $\mathrm{N}$. Factors influencing macrosomia in pregnant women in a tertiary care hospital in Malaysia. J. Obstet. Gynaecol. Res. 2014;40(2):439-444.https://doi.org/10.1111/ jog. 12209

15. Mongelli M., Benzie R., and Condous G. Average fetal weekly weight gain: A novel measure of fetal growth velocity. Journal of Maternal-Fetal and Neonatal Medicine. 2016;29(4):676-679. https:// doi.org/10.3109/14767058.2015.1015981 